\title{
1 Serpentinization as a reactive transport process: The brucite silicification reaction
}

2 Benjamin M. Tutolo ${ }^{1, *}$, Andrew J. Luhmann ${ }^{2}$, Nicholas J. Tosca ${ }^{1}$, William E. Seyfried, Jr. ${ }^{3}$

$3 \quad{ }^{1}$ University of Oxford Department of Earth Sciences, South Parks Road, Oxford UK OX1 3AN

$4{ }^{2}$ Department of Earth and Environmental Science, New Mexico Institute of Mining and 5 Technology, 801 Leroy Place, Socorro, NM 87801, USA

$6{ }^{3}$ Department of Earth Sciences, University of Minnesota, 310 Pillsbury Drive SE, Minneapolis, $7 \quad$ MN 55455, USA

8 *Present address: University of Calgary Department of Geoscience, 2500 University Dr. NW, 9 Calgary, AB T2N 1N4, Canada

\section{Abstract}

11 Serpentinization plays a fundamental role in the biogeochemical and tectonic evolution of the

12 Earth and perhaps many other rocky planetary bodies. Yet, geochemical models still fail to

13 produce accurate predictions of the various modes of serpentinization, which limits our ability to

14 predict a variety of related geological phenomena over many spatial and temporal scales. Here,

15 we utilize kinetic and reactive transport experiments to parameterize the brucite silicification

16 reaction and provide fundamental constraints on $\mathrm{SiO}_{2}$ transport during serpentinization. We

17 show that, at temperatures characteristic of the sub-seafloor at the serpentinite-hosted Lost City

18 Hydrothermal Field $\left(150^{\circ} \mathrm{C}\right)$, the assembly of Si tetrahedra onto $\mathrm{MgOH}_{2}$ (i.e., brucite) surfaces is

19 a rate-limiting elementary reaction in the production of serpentine and/or talc from olivine.

20 Moreover, this reaction is exponentially dependent on the activity of aqueous silica $\left(a_{\mathrm{SiO}_{2}(a q)}\right)$,

21 such that it can be calculated according to the rate law:

$$
\text { Rate }=2.3 \times 10^{-4} a_{\mathrm{SiO}_{2}(a q)}^{1.5}\left(\mathrm{~mol} / \mathrm{m}^{2} / \mathrm{s}\right)
$$


23 Calculations performed with this rate law demonstrate that both brucite and Si are surprisingly

24 persistent in serpentinizing environments, leading to elevated Si concentrations in fluids that can

25 be transported over comparatively large distances without equilibrating with brucite. Moreover,

26 applying this rate law to an open-system reactive transport experiment indicates that advection,

27 preferential flow pathways, and reactive surface area armoring can diminish the net rate of $\mathrm{Si}$

28 uptake resulting from this reaction even further. Because brucite silicification is a fundamentally

29 rate-limiting elementary reaction for the production of both serpentine and talc from forsterite,

30 our new constraints are applicable across the many environments where serpentinization occurs.

31 The unexpected but highly consequential behavior of this simple reaction emphasizes the need

32 for considering serpentinization and many other hydrothermal processes in a reactive transport

33 framework whereby fluid, solute, and heat transport are intimately coupled to kinetically-

34 controlled reactions.

\section{Introduction}

As seawater infiltrates exhumed mantle rocks, a variety of chemical and physical

37 processes ultimately convert mafic minerals (i.e., olivine and pyroxene) to serpentine and

38 accessory phases (Evans et al., 2013; O'Hanley, 1996). For most of Earth's history, this process,

39 known generally as "serpentinization," has played a central role in the long-term evolution of

40 atmospheric, oceanic, and lithospheric properties. Serpentinites and serpentinite-hosted

41 hydrothermal systems host unique, microbial ecosystems (Kelley, 2005; Schrenk et al., 2013),

42 and figure prominently in chemical scenarios for the origins of life on Earth (Martin et al., 2008;

43 Sleep et al., 2011; Sojo et al., 2016) as well as in models for the early chemical evolution of the

44 atmosphere (Kump and Barley, 2007). At a broader level, serpentinizing systems strongly

45 modify the strength and rheological characteristics of the oceanic crust (Escartín et al., 2001), 
46 which, once subducted, influences both the oxidation state and water content of Earth's mantle

47 (e.g., Rüpke et al., 2004). Because the principal reactants and drivers are thought to be common

48 across a range of planetary bodies, some view serpentinization as a fundamental process

49 influencing planetary evolution more generally (e.g., Oze and Sharma, 2005; Sleep et al., 2011;

50 Waite et al., 2017).

Nonetheless, in spite of decades of dedicated research into serpentinization and its wide-

52 ranging implications, the various modes of serpentinization cannot yet be quantitatively

53 predicted from a process-oriented point of view. This, in turn, limits the confidence with which

54 we can extrapolate our knowledge of serpentinization over geologically relevant scales of space

55 and time.

An important example illustrating the disparity between theoretical predictions and field

57 measurements for serpentinizing systems involves the reaction between brucite and dissolved

58 silica $\left(\mathrm{SiO}_{2}(\mathrm{aq})\right)$. Considering only the magnesian end-members, the isochemical

59 serpentinization reaction may be written:

60

61

62

63

64

65

66

67

68

69

70
2 olivine $+3 \mathrm{H}_{2} \mathrm{O}=$ brucite + serpentine .$$
2 \mathrm{Mg}_{2} \mathrm{SiO}_{4}+3 \mathrm{H}_{2} \mathrm{O}=\mathrm{Mg}(\mathrm{OH})_{2}+\mathrm{Mg}_{3} \mathrm{Si}_{2} \mathrm{O}_{5}(\mathrm{OH})_{4}
$$

However, silica sourced from adjacent pyroxene or plagioclase often either precludes brucite formation through a contemporaneous reaction:

3 olivine $+\mathrm{SiO}_{2}(\mathrm{aq})+4 \mathrm{H}_{2} \mathrm{O}=2$ serpentine, $3 \mathrm{Mg}_{2} \mathrm{SiO}_{4}+\mathrm{SiO}_{2}(\mathrm{aq})+4 \mathrm{H}_{2} \mathrm{O}=2 \mathrm{Mg}_{3} \mathrm{Si}_{2} \mathrm{O}_{5}(\mathrm{OH})_{4}$

or silicifies brucite through later-stage infiltration or a fracture reactivation event:

3 brucite $+2 \mathrm{SiO}_{2}(\mathrm{aq})=$ serpentine $+\mathrm{H}_{2} \mathrm{O}$.

$3 \mathrm{Mg}(\mathrm{OH})_{2}+2 \mathrm{SiO}_{2}(\mathrm{aq})=\mathrm{Mg}_{3} \mathrm{Si}_{2} \mathrm{O}_{5}(\mathrm{OH})_{4}+\mathrm{H}_{2} \mathrm{O}$ 
72 Through either pathway, the extreme reactivity of brucite across a broad range of $\mathrm{SiO}_{2}$

73 concentrations dictates that either $\mathrm{SiO}_{2}$ should be quantitatively removed from solution (if

74 brucite is the excess component) or brucite should be quantitatively converted to serpentine (if

$75 \mathrm{SiO}_{2}$ is the excess component) (Fig. 1a). However, although petrographic studies have

76 demonstrated the operation of reactions 1-3 and their higher $a_{S i O_{2}(a q)}$, talc-producing analogues

77 during oceanic serpentinization (e.g., Katayama et al., 2010; Klein et al., 2009), recent

78 measurements of Lost City fluids (Seyfried et al., 2015) suggest that elevated levels of $\mathrm{SiO}_{2}(\mathrm{aq})$

79 can persist in serpentinizing environments, even after flowing through brucite-bearing fractures

80 and massive brucite chimney structures (Ludwig et al., 2006). This, in turn, suggests that "Lost

81 City-type" hydrothermal fluids are not always in equilibrium with their geologic surroundings,

82 and, indeed, that fluid and solute transport in concert with kinetically-controlled geochemical

83 reactions-i.e., reactive transport—govern fluid compositions observed at the seafloor.

$84 \quad$ Reactive transport models have long shown promise for the quantitative prediction of

85 hydrothermal processes, but this ultimate functionality has, to date, remained elusive. Amongst

86 the grand challenges in the continually evolving field of reactive transport modelling, perhaps the

87 most difficult to reconcile involves the estimation of the surface area within a particular rock that

88 will participate in a reaction, which is a function not only of the mineral's intrinsic surface area

89 but also other factors such as flow path geometry (e.g., Helgeson et al., 1984; Noiriel et al., 2009;

90 White and Peterson, 1990). Because this fundamental parameter ultimately dictates the overall

91 pace and extent of geochemical reactions within a particular system, the accuracy of reactive

92 transport simulations hinge largely upon the accuracy of the utilized reactive surface area

93 estimate. This is particularly evident in serpentinizing systems, where most of the reactive 
94 surface area within the rock is generated through feedbacks associated with flow paths generated

95 by the serpentinization reaction itself (Tutolo et al., 2016).

The brucite silicification reaction (reaction 3) presents a tractable yet realistic opportunity

97 to experimentally examine reactive transport processes during serpentinization and illustrate the

98 effects of reactive surface area estimates on predicted results. Here, we utilize both closed- and

99 open-system reactive transport experiments to examine the rates and evolution of this reaction at

$100150^{\circ} \mathrm{C}$, a temperature characteristic of the subsurface at the Lost City Hydrothermal Field

101 (Seyfried et al., 2015), where upwelling hydrothermal fluids are interacting with serpentinized

102 oceanic crust (Früh-Green et al., 2016). We show that, although this reaction is rapid at $150^{\circ} \mathrm{C}$, it

103 is orders of magnitude slower than the rates of olivine dissolution and brucite precipitation.

104 Surprisingly, strong reactive surface area feedbacks can decrease the net rate of this reaction

105 even further, in spite of continued kinetic and thermodynamic drive in its favor. This interesting

106 behavior implies that brucite and elevated $\mathrm{SiO}_{2}(\mathrm{aq})$ concentrations can be surprisingly persistent

107 in serpentinizing systems, which helps to explain the elevated $\mathrm{SiO}_{2}(\mathrm{aq})$ concentrations measured

108 at LCHF, and in turn, implies unexpected alteration phase assemblages and, potentially, limited

109 amounts of $\mathrm{H}_{2}$ production in some serpentinizing systems

110 2. Methods

$111 \quad 2.1 \quad$ Characterization procedures

112 Mineral reactants for experiments were characterized by both Fourier transform infrared

113 (FTIR) spectroscopy and powder X-ray diffraction (XRD) to determine mineralogical

114 composition, and chemical composition of experimental fluids and solids were determined using

115 inductively coupled plasma-optical emission spectroscopy (ICP-OES). FTIR spectra were

116 acquired in transmission mode on optically translucent $\mathrm{KBr}$ disks, which were prepared by first 
117 mixing $\sim 2 \mathrm{mg}$ of sample into $200 \mathrm{mg}$ of dried (at $200^{\circ} \mathrm{C}$ ) $\mathrm{KBr}$ powder, and then compressing the

118 mixture under vacuum to 7 tons in a hydraulic press. XRD measurements were performed at the

119 University of Oxford using a Panalytical Empyrean Series 2 outfitted with a spinning reflection-

120 transmission stage. Samples were mounted on polished silicon background substrates and

121 analyses were performed using a Co Ka source at $40 \mathrm{kV}$ and $40 \mathrm{~mA}$. 5-point Brunauer-Emmett-

122 Teller (BET) specific surface area was measured with $\mathrm{N}_{2}$ gas on the brucite powder (dried at

$12360^{\circ} \mathrm{C}$ ) used in the closed-system experiments at the University of Oxford Begbroke Science

124 Park. The measured specific surface area, $5.41 \pm 0.06 \mathrm{~m}^{2} / \mathrm{g}$, was used to calculate the silica

125 uptake rate in the closed-system experiments.

$126 \mathrm{Mg}, \mathrm{Ca}, \mathrm{Na}$, and $\mathrm{SiO}_{2}$ concentrations in selected fluid samples and the solid brucite ore

127 used in the open-system reactive transport experiment were analyzed by ICP-OES at the Scottish

128 Universities Environmental Research Centre in Glasgow, UK (for the closed-system

129 experiments) and in the University of Minnesota Department of Earth Sciences (for the reactive 130 transport experiment). In the closed-system experiments, Ca concentrations were below the

131 detection limit and variations in Na concentration were smaller than analytical errors and hence

132 neither element is reported. In several samples from the flow-through experiment, $\mathrm{SiO}_{2}$ was

133 measured spectrophotometrically using the molybdate blue method with metol as the reducing

134 agent (Mullin and Riley, 1955) in order to supplement data provided by ICP-OES. Solution $\mathrm{pH}$

135 was measured using a Thermo Scientific ${ }^{\mathrm{TM}}$ Orion $^{\mathrm{TM}} 8103 \mathrm{BN}$ ROSS ${ }^{\mathrm{TM}}$ Combination semi-micro

136 (Oxford) or micro (Minnesota) $\mathrm{pH}$ electrode, calibrated using NIST-traceable 7 and $10 \mathrm{pH}$

137 buffers. X-ray computed tomography (XRCT) imaging was performed on the core assembly

138 described below in the University of Minnesota XRCT laboratory in order to infer extents of

139 physical and chemical evolution that occurred over the course of the flow-through experiment. 
140 The core assembly was imaged in a dry state prior to the experiment, and subsequently imaged in

141 a water-saturated state directly after the experiment and again after it had been flushed with

142 deionized water and dried at $60^{\circ} \mathrm{C}$. The dry core images showed significantly better grayscale

143 contrast than the water-saturated images without any noticeable difference in other volume

144 features and are thus used exclusively in experimental interpretations below. In addition, pre-

145 and post-experiment subsamples of the fracture fill material were analyzed using a Scanning

146 Electron Microscope (SEM) coupled to an Energy Dispersive Spectrometer in the

147 Characterization Facility at the University of Minnesota.

$148 \quad 2.2$ Experimental Methods

149 The goal of this study is to provide insight into the reactive transport process of

150 serpentinization using experimental observations of the elementary brucite silicification reaction.

151 Because no data exist within the literature to calculate the rate of this reaction in even ideal

152 conditions, we first present a series of well mixed, closed-system experiments to quantify its rate.

153 The measured evolution of fluid chemistry as a function of time during these closed-system

154 experiments permits the derivation of a rate law for calculating the rate of silica depletion during

155 brucite silicification as a function of brucite surface area and the activity of aqueous silica.

156 Subsequently, we present an open-system reactive transport experiment that inherently

157 incorporates reactive transport processes, such as surface area armoring and preferential flow

158 pathways. The parameterization derived from the closed-system experiments enables the

159 quantitative interpretation of surface area evolution during the open-system reactive transport

160 experiment. Together, these experimental results provide direct insight into serpentinization in

161 natural systems.

$162 \quad$ 2.2.1 Closed-system experiments 
Reactant fluid in all experiments was prepared to match seawater chloride concentration

$164(0.547 \mathrm{~mol} \mathrm{Cl} / \mathrm{kg}$ solution $)$ by addition of reagent grade $\mathrm{NaCl}$. Consistent with the absence of

165 measurable Mg in LCHF vent fluids (Seyfried et al., 2015), the experimental solutions contained

166 no $\mathrm{Mg}$ and were hence undersaturated with respect to the reactant brucite. Other species typical

167 to seawater and the LCHF vent fluids, such as $\mathrm{Ca}, \mathrm{K}$ and $\mathrm{SO}_{4}$, were also left out of reactant

168 solutions because they are not expected to impact the progress of the focus brucite silicification 169 reaction.

170 Closed-system reactor experiments were performed at the University of Oxford in a $100 \mathrm{~mL}$ 171 pressure vessel manufactured by the Parr Instrument Company (Model 4793). All internal

172 wetted parts are constructed of inert $\mathrm{Ti}$, which were heated in air at $350^{\circ} \mathrm{C}$ for $\sim 4$ hours prior to

173 the experiments in order to produce a thin, oxidized surface coating. A flat PTFE gasket creates

174 a seal between the upper and lower portions of the reaction vessel, which was heated by an

175 external band heater coupled to a K-type thermocouple inserted into a Ti well in direct contact

176 with the reactant fluid. Internal pressure is equilibrium steam saturation pressure, $\sim 4.8$ bar.

177 High-purity (95\%) brucite (102 mg and $105 \mathrm{mg}$ for Expts. 3 and 4, respectively) and a PTFE-

178 coated stir bar were loaded into the vessel prior to sealing. Once sealed, the vessel was secured

179 in an upright position on a magnetically controlled stirrer, the experimental fluid (75.75 $\mathrm{g}$ and

$18075.43 \mathrm{~g}$ in Expts. 3 and 4, respectively) was injected through a port in the top of the vessel, and

181 the temperature controller was set to $150^{\circ} \mathrm{C}$. Total time between fluid loading and reaching

$182150^{\circ} \mathrm{C}$ was $\sim 20-25$ minutes. Throughout the experiments, fluid samples $(\sim 1 \mathrm{~mL})$ were obtained

183 through a Ti dip tube fitted with a $10 \mu \mathrm{m}$ Ti filter positioned within the reactant fluid in order to

184 observe the real-time evolution of fluid chemistry within the vessel. Each fluid sample was

185 preceded by a $\sim 1 \mathrm{~mL}$ rinse sample in order to clear stagnant fluid from within the dip tube prior 
186 to sample acquisition, causing the total mass of reactant fluid to decrease by $\sim 2 \mathrm{~mL}$ after each

187 sample and the fluid/solid ratio to decrease accordingly. Rate calculations take these masses into

188 account. $\mathrm{pH}$ was measured on a $\sim 0.5 \mathrm{~mL}$ aliquot immediately upon sampling, and the remainder

189 of the sampled fluid was acidified and diluted to preserve for later analyses.

190 In two initial experiments (Expts. 1 and 2), the initial $\mathrm{pH}_{21^{\circ} \mathrm{C}}$ of the reactant solution was set

191 to $\sim 8$ in order to approximate the $\mathrm{pH}$ of seawater, and $\mathrm{SiO}_{2}$ concentration of the initial reactant

192 fluid was set to amorphous silica saturation ( 1.8 mmol/kg solution (Gunnarsson and Arnórsson,

193 2000)) using $\mathrm{Na}$ metasilicate nonahydrate $\left(\mathrm{Na}_{2} \mathrm{SiO}_{3} \cdot 9 \mathrm{H}_{2} \mathrm{O}\right)$. However, approximately half of

194 this $\mathrm{SiO}_{2}$ was removed prior to reaching $150^{\circ} \mathrm{C}$, preventing acquisition of meaningful rate data.

195 These experiments will not be discussed further. The presented experiments (Expts. 3 and 4)

196 were performed with an initial $\mathrm{pH}_{21^{\circ} \mathrm{C}} \approx 9.8$, which, because it is near the $\mathrm{pK}$ for silicic acid at

197 room temperature ( 9.86), permitted a much higher initial $\mathrm{SiO}_{2}(\mathrm{aq})$ concentration without

198 precipitating amorphous silica. Although quartz was $\sim 2 \mathrm{x}$ supersaturated in the initial samples

199 from both closed-system experiments, the rate of quartz precipitation this close to equilibrium is

200 slow (Rimstidt and Barnes, 1980) and we therefore do not expect that precipitation of this

201 mineral could have affected our results. In order to capture the rapid rates of reaction at high

$202 \mathrm{SiO}_{2}$ (aq) concentrations, an aggressive sampling protocol was planned for Expt. 3, such that a

203 total of 9 samples were taken within the first 3 hours. Expt. 4 was sampled less frequently and

204 hence was able to continue for longer prior to termination while maintaining similar volumes of 205 experimental fluid.

\section{$206 \quad$ 2.2.2 Reactive transport experiment}

207 A single-pass, hydrothermal flow-through apparatus (Fig. 2a) located in the University of 208 Minnesota Department of Earth Sciences, which has been described in several previous studies 
209 (Luhmann et al., 2017, 2014; Tutolo et al., 2015), was utilized to examine the effect of reactive 210 transport processes on the brucite silicification reaction (Fig. 1b). In brief, the apparatus makes 211 use of a set of 4 Teledyne Isco syringe pumps to facilitate fluid injection and pressurization. A 212 constant outlet pressure (150 bars in this study) is controlled by a model 500D pump, constant 213 confining pressure (200 bars in this study) is maintained by a model 260D pump, and an

214 additional set of 2 model 260D pumps are used to inject the experimental solution at a constant 215 rate $(0.05 \mathrm{~mL} / \mathrm{min}$ in this study) into the core assembly, which is contained within a stainless 216 steel pressure vessel. In the present study, the pressure vessel was maintained at $150^{\circ} \mathrm{C}$ 217 throughout the duration of the experiment by a set of 4 thermocouple-linked Watlow band 218 heaters. While flowing through the heated pressure vessel and reacting with the brucite, the 219 experimental solution only contacted corrosion-resistant pieces made from titanium, Teflon, and 220 PEEK. Permeability was continuously measured during the experiment, and fluid samples were 221 collected after passing through the core. Furthermore, a set of two inert Ti separators with 222 internal, o-ring sealed Ti pistons were utilized on the upstream and downstream side of the 223 pressure vessel in order to prevent the corrosive reactant fluid from coming into contact with the 224 stainless steel interior of the syringe pumps. During typical experiments run with this apparatus 225 (e.g., Luhmann et al., 2014), deionized water is flowed through the core at room temperature 226 prior to the experiment in order to establish baseline permeability. However, in this study, due to 227 the high reactivity of brucite in deionized water at even room temperature, this could not be done 228 without potentially dissolving significant brucite. Thus, the core was pressurized immediately 229 prior to experiment initialization.

230 To facilitate digitization and approximate the fractures characteristic of serpentinization 231 environments, we designed a special Teflon PTFE core assembly with a planar, $1.5 \mathrm{~mm} \times 24.9$ 
$232 \mathrm{~mm} \times 11.34 \mathrm{~mm}$ section of the cylindrical "core" filled with ground brucite ore, held in place

233 with Ti frit endcaps (Fig. 2b). This natural brucite, from Brucite Mine, Nevada, was analyzed by

234 ICP-OES to contain $62.2 \% \mathrm{MgO}, 2.8 \% \mathrm{CaO}, 2.0 \% \mathrm{SiO}_{2}$, and $0.6 \% \mathrm{FeO}$. It consisted of 90-95\%

235 brucite, minor Mg-bearing carbonates, and trace lizardite and was previously used for

236 carbonation experiments by Harrison et al. (2013). The material was first ground and then wet-

237 sieved to select particles in the $75 \mu \mathrm{m}-150 \mu \mathrm{m}$ size range, which were aggregates of many much

238 smaller brucite particles (Fig. 2c), as evidenced by their complete disaggregation during an initial

239 attempt to sonicate them to remove surface particles. A total of $781 \mathrm{mg}$ (dry mass) of brucite was

240 loaded into the core assembly and loaded into a cylindrical Teflon sheath. Assuming a brucite

241 density of $2.368 \mathrm{~g} / \mathrm{cm}^{3}$ (Robie and Hemingway, 1995), the total porosity of the planar fracture

242 was 0.22 , and this value is assumed to be constant in the relevant calculations below. Harrison

243 et al. (2013) report a specific surface area of $6.6 \mathrm{~m}^{2} / \mathrm{g}$ for this material, and we utilize this value

244 for the relevant calculations below. The reactant solution in this experiment was a $547 \mathrm{mmol}$

$245 \mathrm{NaCl} / \mathrm{kg}$ seawater analogue solution, to which $1.7 \mathrm{mmol} \mathrm{SiO}_{2} / \mathrm{kg}$ had been added in the form of

246 silica gel. To facilitate silica dissolution into the solution, we initially raised the $\mathrm{pH}$ of the

247 solution above 10 and heated it in a sealed polyethylene bottle to $60^{\circ} \mathrm{C}$ for several days. The

$248 \mathrm{pH}_{21^{\circ} \mathrm{C}}$ solution was then lowered to 8 by $\mathrm{HCl}$ addition in order to simulate the $\mathrm{pH}$ of seawater.

249 In total, $500 \mathrm{~mL}$ (i.e., the approximate total volume of the two injection pumps) of fluid were

250 injected into the core over the course of the experiment, yielding a cumulative water-to-rock

251 mass ratio of $\sim 640$. The Darcy velocity in this experiment, $\sim 1550 \mathrm{~m} / \mathrm{yr}$, is reasonable, given the

252 (limited) constraints on fluid residence times at $\mathrm{T}>150^{\circ} \mathrm{C}$ in mid-ocean ridge hydrothermal

253 systems (1-3 years (Kadko and Butterfield, 1998)) and an assumed upflow path at LCHF of less

254 than several kilometers (e.g., Seyfried et al., 2015). 
In treating the closed-system experiments, we assumed that the brucite silicification

257 reaction behaves according to the following form of the rate law:

$$
\text { Rate }=k A a_{\mathrm{SiO}_{2}(a q)}^{n}
$$

259 where $k$ is the rate constant for the reaction, $A$ is the surface area of the reactant brucite, and $n$ is

260 the reaction order with respect to the activity of aqueous silica $\left(a_{\mathrm{SiO}_{2}(a q)}\right)$. Equation 4 has the

261 same general form as that derived for the geochemically analogous kaolinite illitization reaction

262 by Chermak and Rimstidt (1990). Following the methodology described by Chermak and

263 Rimstidt (1990), we evaluated the reaction order with respect to $a_{\mathrm{SiO}_{2}(a q)}$ by calculating the $\mathrm{Si}$

264 removal rate in the closed system experiments according to:

$$
\text { rate }=\frac{\Delta C_{S i} m_{\text {soln }}}{\Delta t A}\left(\mathrm{~mol} / \mathrm{m}^{2} / \mathrm{s}\right)
$$

266 where $\Delta C_{S i}$ is the measured change in Si concentration, $m_{\text {soln }}$ is the mass of solution in the

267 reactor, taking into account mass changes due to sampling, $\Delta t$ is the time between samples, and $A$

268 is again the surface area of brucite in the reactor, calculated as the product of the measured BET

269 specific surface area and the mass of brucite in the reactor. Attempts to approximate reductions

270 in brucite surface area in the reactor according to stoichiometric $\mathrm{Mg}$-silicate-forming reactions

271 had no effect on the calculated reaction order or rate constant within the uncertainty of the

272 calculation and hence were ignored. This is consistent with the limited amount of reaction

273 permitted stoichiometrically (Reaction 3 and its talc-producing analogue, which requires 1.33

274 moles of $\mathrm{SiO}_{2}(\mathrm{aq})$ per mole of brucite) between the 1.8 total millimoles of brucite in the reactor

275 and the $\sim 350$ total micromoles of Si removed from solution. 
276 Uncertainties on calculated rates were calculated using standard procedures (Rimstidt, 2014),

277 taking into account the standard deviation of measured Si concentrations and uncertainty on BET

278 surface area. Regression of rates as a function of $a_{\mathrm{SiO}_{2}(a q)}$ was performed according to York et

279 al. (2004), taking into account uncertainties on both calculated $a_{S i O_{2}(a q)}$ (assumed equivalent to

280 the standard deviation of the measured Si concentrations) as well as the uncertainties on the rates

281 calculated using Eqn. 5. We optimized the value of $k$ using an iterative, nonlinear least squares

282 data fitting procedure which minimized the difference between the measured number of moles of

$283 \mathrm{SiO}_{2}$ removed from solution (Table 1) and those calculated using Eqn. 4. In order to remove bias

284 introduced by the variable period between individual samples, a spline function was fit to the

285 measured values as a function of time, and the data were resampled at 10,100, and 1000 evenly

286 spaced intervals. A significant change in the value of the rate constant was observed between 10

287 and 100 samples, but not between 100 and 1000 samples, thus, the reported rate constant is the

288 value obtained after fitting to 1000 evenly spaced subsamples.

$289 \quad 2.4$ Numerical methods

290 The Geochemist's Workbench version 10.0.10 (Bethke and Yeakel, 2015) and

291 PFLOTRAN (Lichtner et al., 2017) were utilized for aqueous speciation and reactive transport

292 calculations, respectively. Because this study focuses on the role of silica in serpentinization

293 reactions, it is important to ensure that the data that we are using to produce thermodynamic

294 calculations of fluid-mineral equilibria agree with available data for the aqueous speciation of

295 silica over the range of temperatures and pressures applicable to serpentinization reactions. As

296 discussed in detail in Tutolo and Tosca (in review), a geochemical thermodynamic database

297 taking explicit account of recent revisions to the speciation of aqueous silica was created using

298 the DBCreate software package (Kong et al., 2013). Briefly, this database was created using 
updated $\mathrm{SiO}_{2}$ (aq) thermodynamic properties presented by Sverjensky et al. (2014), which are

300 consistent with the updated low-temperature quartz solubility measurements of Rimstidt (1997).

301 The $\mathrm{NaHSiO}_{3}$ (aq) complex was removed from the database due to revised experimental

302 measurements that have drawn its stability in seawater into question (Busey and Mesmer, 1977;

303 Felmy et al., 2001; Zarubin and Nemkina, 1990). This complex has a major effect on the

304 aqueous speciation of silica and the overall solubility of silicate minerals at $\mathrm{pH}>\mathrm{pK}$ for silicic

305 acid (see Tutolo and Tosca, in review) and it is thus particularly important to avoid including it

306 in aqueous speciation calculations of water-rock interaction in ultramafic-hosted systems.

\section{3. Results and discussion}

The conversion of brucite to serpentine (reaction 3) can be conceptualized through a

309 simple, epitaxial reaction (Carrado et al., 2000): Si tetrahedra from solution bind to the surface of

310 octahedrally coordinated $\mathrm{Mg}$ (in the form of brucite), forming serpentine (at higher $a_{\mathrm{SiO}_{2}(a q)}$, the

311 resultant mineral is talc (Fig. 1), but the mechanism is identical). This process is exemplified by

312 the results of our closed-system experiments. Specifically, the observed concentrations

313 Nonetheless, in the open-system reactive transport experiment, which was designed to more

314 closely approximate processes characteristic of natural serpentinizing environments, the fluids

315 and reactants are clearly not well-mixed, and only a relatively small proportion of the total

316 brucite surface area is accessible to the flowing fluid. As discussed below, the closed-system

317 experiments provide constraints on the surface-controlled process of brucite silicification under

318 well-mixed conditions, and the laboratory and numerical reactive transport experiments allow us

319 to observe how reactive transport processes can affect the rate and extent of this reaction.

\section{$320 \quad 3.1$ Closed System Experiments}


In spite of the experimental challenges associated with the brucite silicification reaction,

322 our closed-system experiments provide mutually consistent rate measurements, which, in turn,

323 permit kinetic parameterization. Solution analyses indicate Mg concentrations near detection

324 limits in all samples, which is expected, given that equilibrium brucite solubility in our

325 experimental solutions at $\mathrm{pH}_{150^{\circ} \mathrm{C}}=8.2$ is $\sim 10 \mu \mathrm{mol} / \mathrm{kg}$. Thus, within the uncertainty on our

326 calculated $\mathrm{pH}_{150^{\circ} \mathrm{C}}$ (on the order of $\pm 0.1 \mathrm{pH}$ unit), the solutions were very close to

327 thermodynamic equilibrium with respect to brucite. Although the $\mathrm{pH}_{150^{\circ} \mathrm{C}}$ of all samples from

328 both experiments (Table 1$)$ is above the neutral $\mathrm{pH}_{150^{\circ} \mathrm{C}}(\approx 5.8)$, they are all below the $\mathrm{p} K_{150^{\circ} \mathrm{C}}$ for

329 silicic acid (8.75) such that $\mathrm{SiO}_{2}(\mathrm{aq})$ accounts for the majority $(\sim 70 \%)$ of the total aqueous silica

330 in the analyzed solutions, with the remainder existing as $\mathrm{HSiO}_{3}{ }^{-}$. The initial samples in both

331 experiments are characterized by a notably more rapid rate of reaction than the subsequent

332 samples, consistent with an exponential dependence of the reaction rate upon $a_{\mathrm{SiO}_{2}(a q)}$ according

333 to Eqn. 5. Fitting a line to a plot of the rates calculated according to Equation 4 as a function of

334 the $a_{\mathrm{SiO}_{2}(\mathrm{aq})}$ in solution (Fig. 3a) yields the equation:

$$
\log (r)=1.55(0.08) \log a_{\text {SiO2(aq) }}-3.39(0.28)
$$

336 where the values in parentheses are the calculated standard error. This result suggests a reaction 337 order $(n)$ of 1.5 with respect to with respect to $a_{S_{i O}(a q)}$, and subsequent fitting of Eqn. 4 to the 338 measured $\mathrm{SiO}_{2}$ concentrations yields the rate law:

$$
\text { Rate }=2.3 \times 10^{-4} a_{\mathrm{SiO}_{2}(\mathrm{aq})}^{1.5}\left(\mathrm{~mol} / \mathrm{m}^{2} / \mathrm{s}\right)
$$

340 which is applicable at $150^{\circ} \mathrm{C}$ for values of $a_{\mathrm{SiO}_{2}(a q)}$ at least down to $\sim 10 \mu$ molal at seawater ionic

341 strength. Assuming $1 \mathrm{~m}^{2}$ of brucite interacting with $1 \mathrm{~kg}$ of solution, these data indicate that it

342 would take 5.25 days to reduce the $\mathrm{SiO}_{2}(\mathrm{aq})$ concentration from $1.7 \mathrm{mmol} / \mathrm{kg}$ to $170 \mu \mathrm{mol} / \mathrm{kg}$,

343 another 16.6 days to reach $17 \mu \mathrm{mol} / \mathrm{kg}$ and another 52.4 days to remove the 15.3 micromoles of 
344 Si required to achieve a concentration of $1.7 \mu \mathrm{mol} / \mathrm{kg}$. Regardless of the applicability of these

345 specific water-to-rock ratios, the calculations indicate that significant disequilibrium can be

346 maintained during $\mathrm{SiO}_{2}$ transport through serpentinizing rocks. For example, at $a_{\mathrm{SiO}_{2}(a q)} \approx 73$

$347 \times 10^{-6}$ (i.e., the end-member concentration measured in $116^{\circ} \mathrm{C}$ vent fluids at the Lost City

348 Hydrothermal Field (Seyfried et al., 2015)), Eqn. 7 yields a reaction rate of $\sim 1 \times 10^{-10} \mathrm{~mol} / \mathrm{m}^{2} / \mathrm{s}$,

349 which is several orders of magnitude slower than the $150^{\circ} \mathrm{C}$ dissolution rates of brucite, $8.6 \times 10^{-}$

$350{ }^{7} \mathrm{~mol} / \mathrm{m}^{2} / \mathrm{s}$ (Palandri and Kharaka, 2004) and forsterite, $\sim 1 \times 10^{-6} \mathrm{~mol} / \mathrm{m}^{2} / \mathrm{s}$ (Rimstidt et al., 2012).

351 Assuming that brucite growth rates are within 1-2 orders of magnitude of its dissolution rates (as

352 shown experimentally by Pokrovsky and Schott (2004) at $\left.25^{\circ} \mathrm{C}\right)$, this comparison confirms that

353 the assembly of silica tetrahedral sheets onto Mg octahedral sheets (i.e., brucite) is the rate-

354 limiting step during forsterite serpentinization. This assertion is in agreement with the

355 experimental observations of Lin and Clemency (1981) and Saldi et al. (2007), who suggested

356 that the rate-limiting step of the reverse reaction (i.e., antigorite and talc dissolution) is the

357 destruction of tetrahedral Si rather than octahedral Mg sheets.

$358 \quad$ All fluid samples from both closed-system experiments were within the chrysotile

359 stability field in $a_{\mathrm{Mg}^{++}} / a_{\mathrm{H}^{+}}^{2}-a_{\mathrm{SiO}_{2}(\mathrm{aq})}$ space, but the majority of the samples were above the

$360 a_{\mathrm{SiO}_{2}(\mathrm{aq})}$ for talc-chrysotile equilibrium, i.e., $200 \times 10^{-6}$ (Fig. 1a). Solids recovered from Expt. 3

361 showed no crystallographic evidence of silicification, consistent with its relatively short duration

362 and extent of reaction. XRD data from Expt. 4, on the other hand, exhibit a low-angle peak at

$363 \sim 10.2 \AA$, consistent with the formation of kerolite, a hydrated, structurally-related form of talc.

\section{$364 \quad 3.2$ Reactive transport experiment}

365 In total, 0.87 millimoles of dissolved $\mathrm{SiO}_{2}$ were injected into the synthetic, brucite-filled

366 fracture during the reactive transport experiment. Models assuming equilibrium between well- 
367 mixed reactants and products predict that the 13.4 millimoles of brucite within the synthetic

368 fracture would deplete $\mathrm{Si}$ well below detection levels during flow through the core (see below).

369 Nonetheless, solution chemical analyses consistently indicate $\mathrm{SiO}_{2}$ concentrations well above

370 those required for brucite stability exiting the experimental reactor during the first $\sim 110$ hours of

371 the experiment, and a subsequent, rapid transition to even lower net reactivity (Table 2, Fig. 4a).

372 At the conclusion of the experiment, $\sim 0.62$ of the total injected 0.87 millimoles of $\mathrm{SiO}_{2}$ had been

373 deposited within the core. Assuming serpentine growth (see mineralogical constraints below),

374 this amount of silica uptake accounts for the reaction of $\sim 0.41$ millimoles, or $\sim 3 \%$, of the brucite

375 contained within the synthetic fracture.

$376 \mathrm{Mg}$ concentrations in outlet fluids varied from an early-time maximum of $2.3 \mathrm{mmol} / \mathrm{kg}$,

377 down to a minimum of $\sim 44 \mu \mathrm{mol} / \mathrm{kg}$. These solutions tend to be $\sim 1-2$ orders of magnitude

378 undersaturated with respect to brucite and near equilibrium or supersaturated with respect to

379 chrysotile (Table 2). These results, particularly the generally low Mg concentrations and the

380 relatively low supersaturations of chrysotile in the bulk fluid, are consistent with the reaction

381 mechanism discussed above, wherein serpentine is crystallizing by silica condensation upon to

382 brucite surfaces, rather than through heterogeneous crystallization from the bulk fluid phase.

383 In spite of the surface area effects discussed below, the main reason that $\mathrm{SiO}_{2}$

384 concentrations above brucite-serpentine equilibrium are exiting the brucite-filled fracture during 385 the first 110 hours of the experiment is the exponential dependence of the silicification reaction 386 on $a_{\mathrm{SiO}_{2}(a q)}$, as discussed in the previous section. Fig. $4 \mathrm{~b}$ illustrates the expected surface area387 normalized silica uptake rates for the solution samples plotted in Fig. 4a. As a result of this 388 exponential rate dependency, the outlet solutions sampled during the first $\sim 110$ hours of the 389 experiment have an expected reaction rate $\sim 2$ orders of magnitude lower than that calculated for 
390 the injected solution, showing that elevated concentrations of Si can persist even as the solution

391 flows through a packed bed of high-surface-area brucite. After 110 hours of experiment time,

392 however, the outlet $\mathrm{SiO}_{2}$ concentrations indicate that there is simply much less brucite surface

393 area reacting with the fluid. Even though the bulk of fluid flow during this experiment was

394 apparently confined to a relatively limited portion of the fracture, this result is quite surprising

395 because: 1) XRD and FTIR both indicate that even this more reactive portion of the synthetic

396 fracture was still composed almost entirely of brucite after the experiment, and 2) no apparent,

397 abrupt change in the permeability of the synthetic fracture occurred at this time, which would

398 have represented either significant porosity decreases due to serpentine growth or a change in the

399 dominant fluid flow path within the core (Fig. 5). The decline in permeability measured at the

400 beginning of the experiment, significantly prior to the change in reaction regimes, is consistent

401 with pressurization and compaction of the brucite fracture fill, since the pressurization of the

402 core assembly occurred simultaneously with experiment initialization. Because the fluid

403 injection rate was constant throughout the experiment, this permeability did not directly impact

404 fluid residence time within the reactor.

405 We have labeled the transition from the first reaction regime to the second as

406 "precipitation breakthrough", due to the analogy to "dissolution breakthrough" processes which

407 occur whenever high permeability, low reactivity preferential flow paths are generated in, for

408 example, carbonate aquifers (e.g., Dreybrodt, 1990). Regardless of the mechanism, the fact that

409 such high concentrations of $\mathrm{SiO}_{2}$ are exiting the reaction vessel indicates that very little brucite

410 surface area was available for reaction during this stage of the experiment, in spite of the fact that

411 abundant brucite remained both in the "reacted" and "unreacted" regions of the core. Although

412 the small amount of serpentine formed during the experiment precludes identification by XRD, 
413 the location and topology of the set of peaks at 988 and $1087 \mathrm{~cm}^{-1}$ in the post-experiment FTIR

414 spectrum demonstrate serpentine precipitation (Fig. 6c). These principal Si-O absorptions are

415 distinct from all other 2:1 phyllosilicates or modulated versions thereof (i.e., talc, kerolite,

416 sepiolite, etc.; (Farmer, 1974; Russell and Fraser, 1994)) and are instead indicative of poorly

417 crystalline serpentine, akin to the poorly crystalline antigorite identified by Gunnarsson et al.,

$418(2005,2002)$ and the proto-serpentine discussed by Andreani et al. (2007) and Plümper et al.

419 (2012).

\section{$420 \quad 3.3$ Reactive transport simulations of brucite silicification}

421 By incorporating the rate law determined above into reactive transport simulations of our

422 flow-through experiment, we can hone in on specific reactive transport phenomena occurring

423 during the experiment. This allows us to fully understand the implications of the quantified

424 brucite silicification reaction for reactive transport in natural serpentinites. To do this, we ran a

425 series of 200 PFLOTRAN simulations that examine the effects of preferential flow paths and

426 reactive surface area armoring on silica uptake. These simulations illustrate that no more than

427 about $15 \%$ of the brucite surface area in the synthetic fracture participated in the reaction at any

428 given time (Fig. 7a). Indeed, during the post-precipitation breakthrough reaction regime, very

429 little (i.e., less than $\approx 1 \%$ ) of the brucite contained within the core assembly was participating in

430 the reaction, most likely because the easily accessible surface area within this portion of the core

431 had been virtually completely silicified by this time. If, on the other hand, all of the brucite in

432 the synthetic fracture had been participating in the reaction, outlet concentrations would have

433 been on the order of $1 \mu$ molal, or about double the concentration representative of brucite-

434 serpentine equilibrium, and about 50 times lower than the lowest measured concentration. In

435 spite of the fact that only about $1 / 3$ of the fracture showed evidence of silicification in post- 
436 experiment imagery (Fig. 6), these simulations show that even within this portion of the core,

437 only a fraction of the brucite was actually participating in the reaction. This latter observation is 438 consistent with the limited ( $\sim 3 \%)$ extent of brucite conversion to serpentine calculated above.

440 during fluid transport through the core (Fig. 7b). It is particularly interesting to observe the ways

441 in which the coupling between advective Si fluxes, $a_{\mathrm{SiO}_{2}(a q)}$, and brucite reactive surface area

442 availability interact to produce unique equilibration length scales in serpentinizing rocks. For

443 example, these simulations show that in high-flux environments, such as faults, where reactive

444 surface area has been depleted by long-duration fluid fluxes, $\mathrm{Si}$ can be transported over great

445 distances and, thus, seafloor samples of these fluids would be quite representative of the

446 subseafloor reaction zone. At the other end of the spectrum, at the scales of individual olivine

447 crystals (i.e., several hundred micrometers), these simulations show that high Si concentrations

448 generated by orthopyroxene-fluid interaction, such as those producing the pattern of

449 serpentinization shown in Fig. 1, can be laterally persistent if rates of advection/diffusion are

450 sufficiently high, or if the existing brucite surface area has been largely armored during prior

451 stages of serpentinization. These two scales of observation can both be tackled with

452 appropriately scaled reactive transport models, and demonstrate the usefulness of treating

453 serpentinization in a reactive transport sense.

\section{5. Geological Implications}

455 The efficiency and pathway of serpentinization can be dictated by a wide array of 456 processes, yet our study offers unique perspectives on the geological mechanisms that underlie 457 the reactions themselves. From an entirely kinetic point of view, our rate data show that the slow 458 rate of brucite silicification relative to both forsterite dissolution and $\mathrm{MgOH}_{2}$ 
459 dissolution/precipitation allows elevated (i.e., above brucite-serpentine equilibrium)

460 concentrations of Si to persist in moderate-temperature serpentinization environments. That the

461 rate of brucite silicification slows as an exponential function of $a_{\mathrm{SiO}_{2}(a q)}$ indicates that $\mathrm{Si}$ can be

462 transported over comparatively large length scales, particularly when considering the reactive

463 transport processes we have discussed.

464 Both our laboratory and numerical reactive transport experiments illustrate that

465 traditional geochemical models of serpentinization cannot produce accurate, process-oriented

466 predictions of serpentinizing systems. For example, the presence of brucite in serpentinized

467 rocks has been used to infer excessively low concentrations of $\mathrm{SiO}_{2}$ concentrations in reacting

468 fluids (e.g., Beard and Hopkinson, 2000). In addition, at face value, simplified rate formulations

469 (e.g., Martin and Fyfe (1970)) and the activity diagram plotted in Fig. 1 would appear to suggest

470 that serpentinization should proceed rapidly and irreversibly in all seafloor hydrothermal

471 systems, with brucite fully reacting out in the presence of even negligible aqueous silica.

472 However, we have shown that the exponential dependence of the rate of this reaction on

$473 a_{\mathrm{SiO}_{2}(a q)}$, as well as reactive surface area armoring, permit $\mathrm{SiO}_{2}$ concentrations to remain

474 metastably elevated. As a consequence, these dynamic factors allow brucite to persist in such

475 systems, particularly when the brucite surfaces are separated from primary flow paths by

476 serpentine. From the fluid perspective, our results also help to explain recent reports of elevated

477 Si fluids emitting from orifices in the massive brucite chimneys at the Lost City Hydrothermal

478 Field (Seyfried et al., 2015). Because elevated Si fluxes in serpentinizing environments are

479 thought to govern the partitioning of Fe into alteration phases and, consequently, the amount of

$480 \mathrm{H}_{2}$ generated from Fe oxidation (Bach et al., 2006; Frost and Beard, 2007; Syverson et al., 2017),

481 our new kinetic and reactive transport constraints suggest that elevated Si and its consequent 
482 effects on $\mathrm{H}_{2}$ production and biological habitability can be surprisingly prevalent in

483 serpentinizing environments.

484 Brucite silicification is a fundamentally rate-limiting elementary reaction for the

485 production of both serpentine and talc from forsterite. Thus, our new constraints are applicable

486 across the many environments where serpentinization occurs. The surprising kinetic behavior of

487 this simple reaction, in turn, emphasizes the need for considering serpentinization and many

488 other hydrothermal processes as reactive transport processes in which fluid, solute, and heat

489 transport are intimately coupled to kinetically-controlled serpentinization reactions. Persistent

490 challenges in the application of reactive transport models to geologic systems, particularly the

491 estimation of reactive surface area within geologic media, will thus need to be the subject of

492 continued, focused experimental and computational investigations.

\section{Acknowledgements}

494 This research used samples and/or data provided by the International Ocean Discovery Program

495 (IODP). Portions of this research were supported by the United States National Science

496 Foundation under grant number 1426695. We thank Glenn Hammond for help with the

497 PFLOTRAN simulations, Nicholas Seaton for assistance with SEM analysis, Brian Bagley for

498 assistance with XRCT imaging and processing, and Anna Harrison for providing the brucite used

499 in the reactive transport experiment. The Characterization Facility at the University of

500 Minnesota, where the SEM imaging was performed, receives partial support from NSF through

501 the MRSEC program. The authors wish to thank two anonymous reviewers and Associate Editor

502 Mike Bickle, whose critical evaluation of this manuscript helped to improve its clarity.

504 References 
Bach, W., Paulick, H., Garrido, C.J., Ildefonse, B., Meurer, W.P., Humphris, S.E., 2006. Unraveling the sequence of serpentinization reactions: Petrography, mineral chemistry, and petrophysics of serpentinites from MAR $15^{\circ}$ N (ODP Leg 209, Site 1274). Geophys. Res.

Beard, J.S., Hopkinson, L., 2000. A fossil, serpentinzation-related hydrothermal vent, Ocean Lett. 33, 4-7. doi:10.1029/2006GL025681 Drilling Program Leg 173, Site 1068 (Iberia Abyssal Plain): Some aspects of mineral and

Bethke, C.M., Yeakel, S., 2015. The Geochemist'sWorkbench ${ }^{\circledR}$ Release 10.0 - Reference Manual.

Busey, R.H., Mesmer, R.E., 1977. Ionization equilibriums of silicic acid and polysilicate fluid chemistry. J. Geophys. Res. 105, 16,527-16,539. doi:10.1029/2000JB900073

Carrado, K.A., Xu, L., Gregory, D.M., Song, K., Seifert, S., Botto, R.E., 2000. Crystallization of

Chermak, J.A., Rimstidt, J.D., 1990. The hydrothermal transformation rate of kaolinite to a layered silicate clay as monitored by small-angle X-ray scattering and NMR. Chem. Mater. 12, 3052-3059. doi:10.1021/cm000366a muscovite/illite. Geochim. Cosmochim. Acta 54, 2979-2990. doi:10.1016/0016$7037(90) 90115-2$

Dreybrodt, W., 1990. The Role of Dissolution Kinetics in the Development of Karst Aquifers in Limestone: A Model Simulation of Karst Evolution. J. Geol. 98, 639-655. 
Evans, B.W., Hattori, K., Baronnet, A., 2013. Serpentinite: What, why, where? Elements 9, 99106. doi:10.2113/gselements.9.2.99

Farmer, V.C., 1974. Infrared Spectra of Minerals. Mineral. Soc. London 149-151. doi:10.1180/mono-4

Felmy, A.R., Cho, H., Rustad, J.R., Mason, M.J., 2001. An aqueous thermodynamic model for polymerized silica species to high ionic strength. J. Solution Chem. 30, 509-525.

Frost, R.B., Beard, J.S., 2007. On silica activity and serpentinization. J. Petrol. 48, 1351-1368.

Früh-Green, G.L., Orcutt, B.N., Green, S., Cotterill, C., 2016. Expedition 357 Preliminary doi:10.1093/petrology/egm021 doi:10.1023/A:1010382701742

543 Harrison, A.L., Power, I.M., Dipple, G.M., 2013. Accelerated carbonation of brucite in mine

Gunnarsson, I., Arnórsson, S., 2000. Amorphous silica solubility and the thermodynamic properties of $\mathrm{H}_{4} \mathrm{SiO}_{4}{ }^{\circ}$ in the range of $0^{\circ}$ to $350^{\circ} \mathrm{C}$ at $\mathrm{P}($ sat $)$. Geochim. Cosmochim. Acta 64, 2295-2307. doi:10.1016/S0016-7037(99)00426-3

Helgeson, H.C., Murphy, W.M., Aagaard, P., 1984. Thermodynamic and kinetic constraints on reaction rates among minerals and aqueous solutions. II. Rate constants, effective surface 
area, and the hydrolysis of feldspar. Geochim. Cosmochim. Acta 48, 2405-2432. doi:10.1016/0016-7037(84)90294-1

Kadko, D., Butterfield, D.A., 1998. The relationship of hydrothermal fluid composition and crustal residence time to maturity of vent fields on the Juan de Fuca Ridge. Geochim. Cosmochim. Acta 62, 1521-1533. doi:10.1016/S0016-7037(98)00088-X

Katayama, I., Kurosaki, I., Hirauchi, K. ichi, 2010. Low silica activity for hydrogen generation

Kong, X.Z., Tutolo, B.M., Saar, M.O., 2013. DBCreate: A SUPCRT92-based program for producing EQ3/6, TOUGHREACT, and GWB thermodynamic databases at user-defined T and P. Comput. Geosci. 51, 415-417. doi:10.1016/j.cageo.2012.08.004

Kump, L.R., Barley, M.E., 2007. Increased subaerial volcanism and the rise of atmospheric oxygen 2.5 billion years ago. Nature 448, 1033-6. doi:10.1038/nature06058

Lichtner, P.C., Hammond, G.E., Lu, C., Karra, S., Bisht, G., Andre, B., Mills, R.T., Kumar, J., 
Lin, F.C., Clemency, C. V., 1981. The dissolution kinetics of brucite, antigorite, talc, and phlogopite at room temperature and pressure. Am. Mineral. 66, 801-806.

572 Ludwig, K.A., Kelley, D.S., Butterfield, D.A., Nelson, B.K., Früh-Green, G., 2006. Formation 573 and evolution of carbonate chimneys at the Lost City Hydrothermal Field. Geochim.

Maher, K., Steefel, C.I., DePaolo, D.J., Viani, B.E., 2006. The mineral dissolution rate

Luhmann, A.J., Tutolo, B.M., Bagley, B.C., Mildner, D.F.R., Scheuermann, P., Feinberg, J., Seyfried, W.E., 2017. Chemical and physical changes during seawater flow through intact dunite cores: An experimental study at $150-200^{\circ} \mathrm{C}$. Geochim. Cosmochim. Acta. doi:10.1016/j.gca.2017.07.020

Martin, B., Fyfe, W.S., 1970. Some experimental and theoretical observations on the kinetics of hydration reactions with particular reference to serpentinization. Chem. Geol. 6, 185-202. doi:10.1016/0009-2541(70)90018-5

Martin, W., Baross, J., Kelley, D., Russell, M., 2008. Hydrothermal vents and the origin of life. Nat. Rev. Microbiol. 6, 805-814. doi:10.1038/nrmicro1991 
Mullin, J.B., Riley, J.P., 1955. The colorimetric determination of silicate with special references to sea and natural water. Anal. chim. Acta 12, 162-176.

Noiriel, C., Luquot, L., Madé, B., Raimbault, L., Gouze, P., Van Der Lee, J., 2009. Changes in reactive surface area during limestone dissolution: An experimental and modelling study. Chem. Geol. 265, 160-170.

O’Hanley, D.S., 1996. Serpentinites. Oxford University Press.

Oze, C., Sharma, M., 2005. Have olivine, will gas: Serpentinization and the abiogenic production of methane on Mars. Geophys. Res. Lett. 32, 1-4. doi:10.1029/2005GL022691

Palandri, J.L., Kharaka, Y.K., 2004. A compilation of rate parameters of water-mineral interaction kinetics for application to geochemical modeling. USGS Open File Rep. 20041068, 71. doi:10.1098/rspb.2004.2754

Pokrovsky, O.S., Schott, J., 2004. Experimental study of brucite dissolution and precipitation in aqueous solutions: Surface speciation and chemical affinity control. Geochim. Cosmochim. Acta 68, 31-45. doi:10.1016/S0016-7037(03)00238-2

Rimstidt, J.D., 2014. Geochemical Rate Models. Cambridge University Press, Cambridge, UK.

Rimstidt, J.D., 1997. Quartz solubility at low temperatures. Geochim. Cosmochim. Acta 61, 2553-2558. doi:10.1016/S0016-7037(97)00103-8

Rimstidt, J.D., Barnes, H.L., 1980. The kinetics of silica-water reactions. Geochim. Cosmochim. Acta. doi:10.1016/0016-7037(80)90220-3

Rimstidt, J.D., Brantley, S.L., Olsen, A.A., 2012. Systematic review of forsterite dissolution rate data. Geochim. Cosmochim. Acta 99, 159-178. doi:10.1016/j.gca.2012.09.019 
613 Robie, R.A., Hemingway, B.S., 1995. Thermodynamic properties of minerals and related

614 substances at $298.15 \mathrm{~K}$ and 1 bar (105 Pascals) pressure and at higher temperatures.

615 Rüpke, L.H., Morgan, J.P., Hort, M., Connolly, J.A.D., 2004. Serpentine and the subduction

616 zone water cycle. Earth Planet. Sci. Lett. 223, 17-34. doi:10.1016/j.epsl.2004.04.018

617 Russell, J.D., Fraser, A.R., 1994. Infrared methods. Clay Mineral. Spectrosc. Chem. Determ.

$618 \quad$ Methods 11-67. doi:10.1007/978-94-011-0727-3_2

619 Saldi, G.D., Köhler, S.J., Marty, N., Oelkers, E.H., 2007. Dissolution rates of talc as a function 620 of solution composition, $\mathrm{pH}$ and temperature. Geochim. Cosmochim. Acta 71, 3446-3457.

622 Schrenk, M.O., Brazelton, W.J., Carolina, N., Lang, S.Q., 2013. Serpentinization, Carbon, and Deep Life. Rev. Mineral. 75, 575-606. doi:10.2138/rmg.2013.75.18

624 Seyfried, W.E., Pester, N.J., Tutolo, B.M., Ding, K., 2015. The Lost City hydrothermal system: 625 Constraints imposed by vent fluid chemistry and reaction path models on subseafloor heat 626 and mass transfer processes. Geochim. Cosmochim. Acta 163, 59-79. doi:10.1016/j.gca.2015.04.040

628 Sleep, N.H., Bird, D.K., Pope, E.C., 2011. Serpentinite and the dawn of life. Philos. Trans. R. Soc. B 366, 2857-2869. doi:10.1098/rstb.2011.0129

630 Sojo, V., Herschy, B., Whicher, A., Camprubi, E., Lane, N., 2016. The origin of life in alkaline hydrothermal vents. Astrobiology 16, 181-197. doi:10.1089/ast.2015.1406

632 Sverjensky, D.A., Harrison, B., Azzolini, D., 2014. Water in the deep Earth: The dielectric 633 constant and the solubilities of quartz and corundum to $60 \mathrm{~kb}$ and $1200^{\circ} \mathrm{C}$. Geochim. 
635
Syverson, D.D., Tutolo, B.M., Borrok, D.M., Seyfried, W.E., 2017. Serpentinization of olivine at $300{ }^{\circ} \mathrm{C}$ and 500 bars: An experimental study examining the role of silica on the reaction path and oxidation state of iron. Chem. Geol. 475, 122-134. doi:10.1016/j.chemgeo.2017.11.006

Tutolo, B.M., Luhmann, A.J., Kong, X.Z., Saar, M.O., Seyfried, W.E., 2015. $\mathrm{CO}_{2}$ sequestration in feldspar-rich sandstone: Coupled evolution of fluid chemistry, mineral reaction rates, and hydrogeochemical properties. Geochim. Cosmochim. Acta 160, 132-154. doi:10.1016/j.gca.2015.04.002

Tutolo, B.M., Mildner, D.F.R., Gagnon, C.V.L., Saar, M.O., Seyfried, W.E., 2016. Nanoscale constraints on porosity generation and fluid flow during serpentinization. Geology 44, 103106. doi:10.1130/G37349.1

Tutolo, B.M., Tosca, N.J., in review Experimental examination of Mg-silicate - carbonate interactions during lacustrine carbonate reservoir formation.

Waite, J.H., Glein, C.R., Perryman, R.S., Teolis, B.D., Magee, B.A., Miller, G., Grimes, J., Perry, M.E., Miller, K.E., Bouquet, A., Lunine, J.I., Brockwell, T., Bolton, S.J., 2017. Cassini finds molecular hydrogen in the Enceladus plume: Evidence for hydrothermal processes. Science (80-. ). 356, 155-159. doi:10.1126/science.aai8703

White, A.F., Peterson, M.L., 1990. Role of reactive-surface-area characterization in geochemical kinetic models. Chem. Model. Aqueous Syst. II (eds DC Melchoir RL Bassett) Chap 35, $461-475$.

York, D., Evensen, N.M., Martínez, M.L., De Basabe Delgado, J., 2004. Unified equations for 
656 the slope, intercept, and standard errors of the best straight line. Am. J. Phys. 72, 367.

657 doi:10.1119/1.1632486

658 Zarubin, D.P., Nemkina, N.V., 1990. The solubility of amorphous silica in an alkaline aqueous

659 medium at a constant ionic strength. Russ. J. Inorg. Chem.

660 